\title{
Habitat Preference and Population Ecology of Limpets Cellana karachiensis (Winckworth) and Siphonaria siphonaria (Sowerby) at Veraval Coast of Kathiawar Peninsula, India
}

\author{
Julee Faladu, Bhavik Vakani, Paresh Poriya, and Rahul Kundu \\ Department of Biosciences, Saurashtra University, Rajkot, Gujarat 360005, India \\ Correspondence should be addressed to Rahul Kundu; rskundu@sauuni.ernet.in
}

Received 7 May 2014; Revised 6 July 2014; Accepted 20 July 2014; Published 17 August 2014

Academic Editor: Wen-Cheng Liu

Copyright (c) 2014 Julee Faladu et al. This is an open access article distributed under the Creative Commons Attribution License, which permits unrestricted use, distribution, and reproduction in any medium, provided the original work is properly cited.

Present study reports the habitat preference and spatiotemporal variations in the population abundance of limpets Cellana karachiensis and Siphonaria siphonaria inhabiting rocky intertidal zones of Veraval coast, Kathiawar Peninsula, India. The entire intertidal zone of the Veraval coast was divided into five microsampling sites based on their substratum type and assemblage structure. Extensive field surveys were conducted every month in these microsampling sites and the population abundance of two limpet species was analyzed using belt transect method. The results revealed that $C$. karachiensis was the dominating species at microsampling Site-1 (having rocky substratum) possibly due to its ability to tolerate high desiccation, salinity, and temperature fluctuations, while the S. siphonaria was found to be the most dominating species at microsampling Site-2 (having rocky substratum with abundant algal population) possibly due to their preference for the perpetual wet areas. The study also indicated that $S$. siphonaria preferred upper littoral zone where the green algae were abundant while C. karachiensis preferred the spray zone, where it faces almost no competition for space and food with other molluscs. The condition of the spray zone is very harsh for other species to survive.

\section{Introduction}

Rocky shores are one of the most easily accessible marine habitats and also transition zone between land and the sea. Organisms of rocky shores are strongly influenced by two processes, tidal region and exposure to wave action [1]. During the low tide, the phenomenon of zonation is manifested in the form of horizontal bands or zones for the intertidal organisms [2]. Animals and plants on intertidal rocky shores have long been studied very intensively $[3,4]$ and not only are these ecological studies valuable source for the status of the particular ecological area but also contribute immensely to understanding other similar kinds of ecological habitats [2]. Veraval coast off the Arabian Sea is having a broad continental shelf which harbours a very rich biota $[4,5]$. Intertidal zone of this coastline is characterized by different structural variations of substratum like bare rocky area, area with algal cover, uneven rocky area with more number of pools and crevices, and so forth. All these habitats show their typical assemblage structure [6]. Two species of limpet, Cellana karachiensis (patellogastropoda) and Siphonaria siphonaria (heterogastropoda), are found abundantly in the entire Veraval coast and beyond. Limpets are known to play a key role in structuring the marine intertidal ecosystems. These gastropods, therefore, have been subjected to numerous investigations over the years $[4,6]$. It was observed from the literature that very few studies have been carried out on the spatiotemporal variations in the population ecology of limpets from Indian coasts. Sukumaran and Krishnaswamy [7] studied the ecological response of salinity changes in C. radiata from Madras coast. Rao and Ganpati [8] have reported the resistance capabilities of $C$. radiata to high temperature, salinity, and desiccation stress. Investigations were also carried out on the limiting factors for the distribution and homing behaviour of limpets as the distribution is believed to be largely dependent on the homing capabilities found in these species [7]. However, little is known about the distribution and frequency of phenotype 


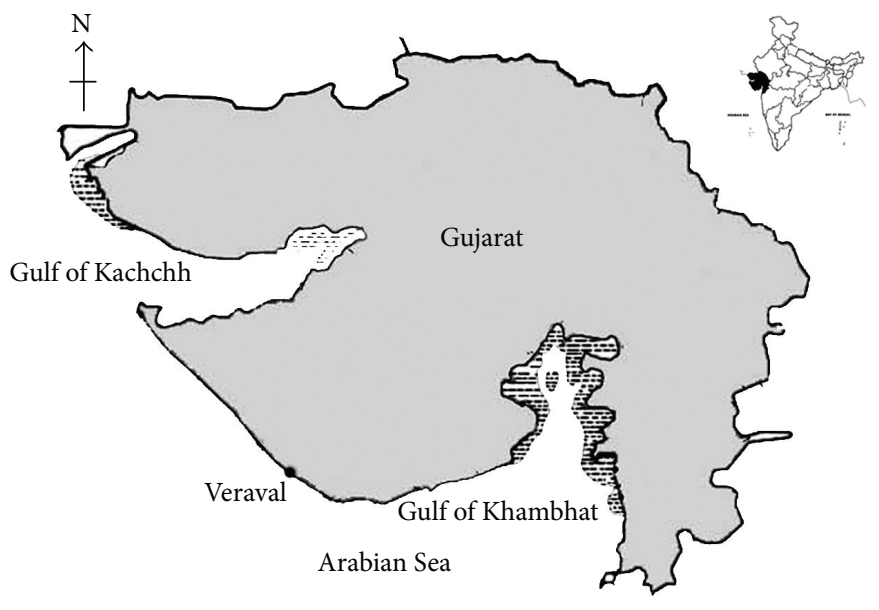

FIGURE 1: Map showing the study location along the South Saurashtra coastline off Arabian Sea. The Veraval coast was subdivided into five microsampling sites.

and genetic variability of limpets in relation to contrasting and changing environmental conditions and geographical variations $[1,6,9,10]$. The homing behaviour and its role in survival against limiting factors like salinity, temperature, and desiccation on Patella vulgata, P. depressa, P. aspera, and Patina pellucid had been studied by Cook et al. [11]. Orton [12] and Eaton [13] studied the homing behaviour in Patella vulgata, Collisella limatula, and Cellana nigrolineata and reported that the typical homing behaviour is possibly helping the animals against desiccation. Black [14] observed that the limpets like Patelloida alticostata usually return to their home scar after grazing at the upper or middle littoral zone during high tides. S. B. Cook and C. B. Cook $[15,16]$ observed that pulmonate limpets like Siphonaria normalis and Siphonaria alternata moved forward during neap tides for longer time than the spring tides. These movements largely contribute to the distribution of the limpets on a typical rocky shore $[13,15]$. Seasonal variation in biochemical composition [17], salinity and desiccation tolerance $[8,18]$, and colour banding pattern [19] has been studied in Cellana radiata from the Indian coasts. Some of the population ecological parameters were also studied on the limpets from west coast of India $[1,20]$. Population ecology and coexistence of limpets Lottia gigantea and different species of Acmaea sp. in the intertidal belt have been studied by Stimson [21]. Blackmore [22] studied the zonal distribution of $P$. vulgata, while shell proportions and texture in limpets were reviewed by Vermeij [23]. The tolerance of limpets to desiccation stress was studied by Balaparameswara Rao and Ganapati [24], Rao and Ganpati [8], Branch [25], and Malli et al. [18]. Present study, therefore, reports the spatiotemporal variations in the distribution, population structure, and habitat preference of two common limpets Cellana karachiensis and Siphonaria siphonaria inhabiting different strata of the selected sites which has rich marine biota with their unique assemblage types at Veraval coast, Kathiawar Peninsula, India.

\section{Materials and Methods}

Kathiawar Peninsula is located at south western part of Gujarat state (India) which occupies a total of $865 \mathrm{~km}$ coastal stretch. The present study was conducted at Veraval $\left(20^{\circ} 54^{\prime} \mathrm{N}\right.$ and $70^{\circ} 22^{\prime} \mathrm{E}$ ) on the western coast of India (Figure 1). The sampling location, along the selected coastline, is about $2 \mathrm{~km}$ long. The entire intertidal zone of this area was divided into five microsampling sites on the basis of their substratum type and their assemblages (Table 1).

The study was conducted on monthly basis from August 2013 to February 2014. During this time span, baseline database of the limpet diversity and its habitat preference in different stratum around the rocky intertidal shore of the coastline were prepared. Belt transect method was followed for the collection of the ecological data, while quadrat method was used to measure the structural attributes of the intertidal fauna [26]. Quadrats of $0.25 \mathrm{~m}^{2}$ size were laid by following oblique direction to cover maximum area on the intertidal zones. Ecological attributes like population density, abundance, and percent frequency values of selected limpet species were studied and calculated for each vertical zone for each of the microsampling sites (or strata). In this report, however, only the abundance values were considered for an almost accurate expression of the current ecological status of these species [1]. The obtained data were subjected to different statistical analyses for their cumulative acceptability. Significance of spatial and temporal variations was compared by using single factor ANOVA. All statistical analyses were done as per Sokal and Rohlf [27].

\section{Results and Discussion}

Veraval, being the largest fish landing site of India, is an important sea shore from biological and economical point of view. The human interference at this area is ever increasing 
TABLE 1: Description of the microsampling sites.

\begin{tabular}{ll}
\hline Microsampling sites & Site description \\
\hline S-1 & $\begin{array}{l}\text { This sampling microsite has bare rocky substratum with fewer sharp edges and has a gradient } \\
\text { slope. Limpets found in this area were comparatively large. }\end{array}$ \\
\hline S-2 & $\begin{array}{l}\text { This sampling microsite has rocky substratum with plentiful algal growth. Chlorophyceae like } \\
\text { Ulva lactuca at upper to middle littoral zone was the dominant algal form observed during the } \\
\text { entire study period. }\end{array}$ \\
\hline S-3 & $\begin{array}{l}\text { This sampling microsite has more pools and puddles than the other sampling microsites. The } \\
\text { pools and puddles with moderate algal growth were sharp edged and submerged. In this site, sea } \\
\text { anemone and other gastropods like Cerithium sp. were found as most common macrofaunal } \\
\text { forms. }\end{array}$ \\
\hline S-4 & $\begin{array}{l}\text { The area of this sampling microsite has network of crevices. Gastropods like Turbo bruneus and } \\
\text { sponge like Tethya sp. were the most common life forms. Limpets and other molluscs were also } \\
\text { found in the crevices. }\end{array}$ \\
\hline S-5 & $\begin{array}{l}\text { The rocky surface of this microsampling site is typically flat with less pools and puddles. } \\
\text { Congregation of large Siphonaria siphonaria was the most common animal of this site. }\end{array}$ \\
\hline
\end{tabular}



FIGURE 2: Monthly variation in abundance of Cellana karachiensis at the different microsampling sites (S-1: Site-1, S-2: Site-2, S-3: Site-3, S-4: Site-4, S-5: Site-5).

which affects the marine ecosystem. The whole western belt of India is considerably being exploited heavily by various kinds of industries [28]. Rocky substratum of Veraval consists of many pools, puddles, and crevices which makes it biologically and ecologically important niche. These types of niche and algal cover on the littoral area offer variety of habitats for limpets, hermit crabs, annelids, flat worms, sea anemones, and sponges [28]. Rocky substratum of this area furnished the ground for varied algal species like Ulva and Enteromorpha that provides the ideal habitat for varied intertidal fauna [29]. In the present study, one of the population ecological attributes, abundance, of two limpet species was calculated for each microsampling site to understand their distributional pattern in different assemblages of Veraval coast. The pattern of the temporal variations of both species was more or less similar except during the winter season. Significant spatial variations in the abundance value were observed in the microsampling sites. It appears that the substratum characteristics like pools, puddles, crevices, and algal cover might have affected the distribution of animal population in the intertidal zones $[4,19]$.
In the present study, the observed abundance values of Cellana karachiensis showed significant spatial and temporal variations in microsampling sites studied (Figure 2). Among the spray zone of different sites, high abundance value was observed at S-1. In case of the upper littoral zone, high abundance of this species was observed at S-1 and S-5. Similar trend was observed in case of the middle littoral zone. However, C. karachiensis was absent in microsampling site S-3. In general, abundance value was higher at spray zone than the other vertical zones and in most cases lower littoral zone was devoid of $C$. karachiensis. The cumulative site-wise results indicated that S-1 had highest while S-3 had the lowest abundance value compared to that of the other microsampling sites. It was observed that the other preferred sites for C. karachiensis were S-2 which has more algal cover followed by S- 4 with numerous crevices and S-5 with flattened substratum (Figure 2).

In the present study, it was observed that the spray zone of all the microsampling sites had higher abundance values of Siphonaria siphonaria than that of the other vertical zones. This species was absent in lower littoral zone of all 


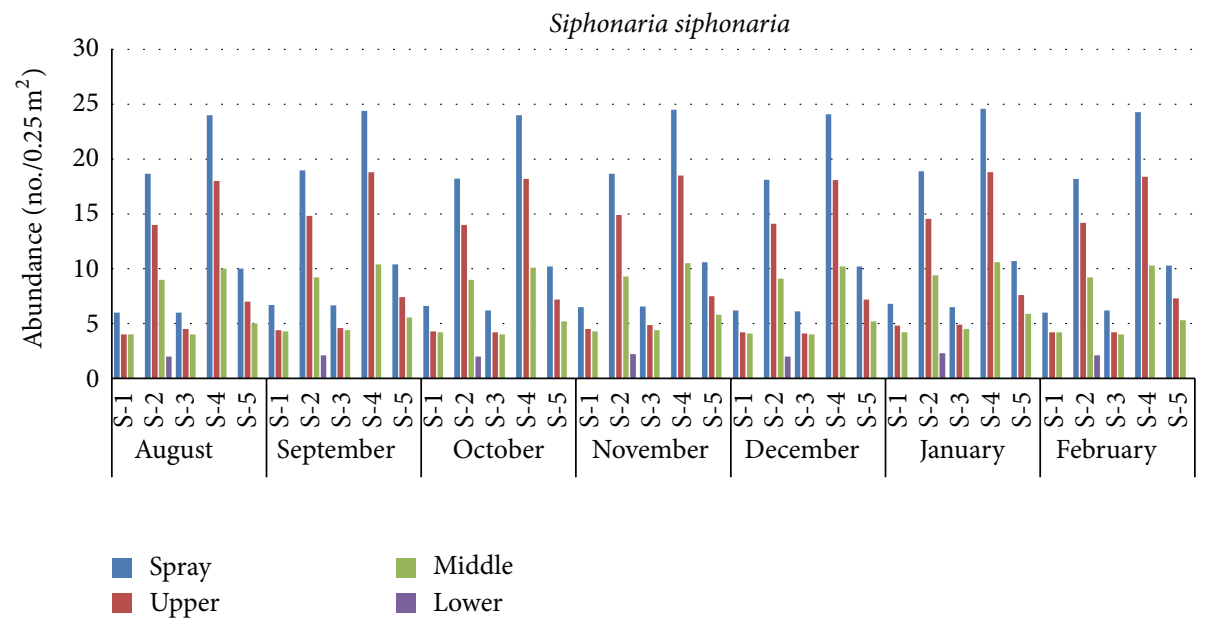

FIGURE 3: Monthly variation in the population abundance of Siphonaria siphonaria at different microsampling sites (S-1: Site-1, S-2: Site-2, S-3: Site-3, S-4: Site-4, S-5: Site-5).

microsites except S-2. However, the upper zone showed less abundance value than the spray zone (Figure 3). In general, the abundance of $S$. siphonaria showed a decreasing trend from spray to lower zones in all the microsampling sites; namely, highest abundance value was observed in the spray zone at S-4 followed by S-2, S-5, and S-1 and the lowest value was observed at $S-3$. Amongst the microsampling sites studied, the population of Siphonaria siphonaria showed a contrasting pattern compared to that of C. karachiensis. Population abundance of S. siphonaria was high at S-4 which may be due to the availability of small habitat in the form of networks of crevices, followed by S-2 which had more algal growth than that of other sampling sites. Results of the ANOVA showed highly significant spatial variations in the population abundance for both species; however, no significant temporal variations were observed (Table 2). Limpets like C. scabra and Notoacmea petterdi exhibit very rigid homing habits or movements, show less response to seasonal changes, and remain faithful to a home scar for most of their lives [30, 31]. This movement or homing habit influences the population dynamics of these species in the intertidal zones [1]. On the basis of abundance value of $C$. karachiensis, the highest population was observed in the spray zone of S-1 followed by S-5 while the lowest population abundance was observed at S-3.

The S-1 microsampling site consists of bare rocky substratum having less sharp-edged crevices and is covered with less algal growth [1]. Fewer sharp edged crevices with gradient slope of this site create harsh conditions to survive [6]. Only those animals can survive which have the capacity to tolerate high desiccation, fluctuation in salinity, and temperature [1, 6]. Desiccation may also limit the zonation indirectly and it was reported that desiccation was the only physical factor which regularly impose limits to the limpet population in each of vertical zones [9]. However, in the present study the periodical desiccation at the spray zone was not a limiting factor for C. karachiensis which exhibits limited movements as homing movement [32]. Thus, the desiccation, salinity and
TABLE 2: Results of the one way ANOVA for the spatial and temporal variations in the abundance values of the species studied in each of the littoral zone of the five microsampling sites.

\begin{tabular}{ccccc}
\hline & Spray & Upper & Middle & Lower \\
\hline \multicolumn{5}{c}{ Spatial variation $(f$-critical: 2.6896$)$} \\
Cellana karachiensis & $14.961^{*}$ & $10.245^{*}$ & $84.399^{*}$ & 0 \\
Siphonaria siphonaria & $57.162^{*}$ & $27.272^{*}$ & $11.337^{*}$ & $23.153^{*}$ \\
\hline Temporal variation & $(f$-critical: & $2.4453)$ \\
Cellana karachiensis & 0.0148 & 0.0234 & 0.0975 & 0 \\
Siphonaria siphonaria & 0.0043 & 0.0106 & 0.0244 & 0.003 \\
\hline
\end{tabular}

The $*$ sign denotes significance at $P<5 \%$.

temperature fluctuations in the spray zone are the limiting factors for other animals. However, limpets are well adapted to this harsh conditions. The movement during high tide or the homing behaviour plays an important role in the distribution of limpets which prefer the dry spray zone. $C$. karachiensis and S. siphonaria can tolerate wide range of desiccation and fluctuations in salinity and temperature [1]. Several species such as C. exarata and Patella granularis inhabiting the dry high shore areas have highly developed homing movements [33, 34]. However, limpets like Patella vulgata, Collisella limatula, and Cellana nigrolineata prefer wet habitat and thus did not exhibit well developed homing movements $[12,13]$. It was also reported that the limpet Siphonaria normalis often failed to home in on damp areas and the survival of transplanted animals was much less in dry exposed sites [35].

On the other hand, the microsampling site S-2 has more algal cover than all other sites but was found to be less preferred by C. karachiensis. However, S. siphonaria was noted at site S-2 in more numbers though the species was most abundant at site $\mathrm{S}-4$. This can be due to the fact that, in limpets, clustering may be important for reducing desiccation by retaining small quantities of water during exposed hours [35]. Since most siphonarians graze on macroalgae and thin 
film of algae that grows on rocks, the feeding habits may also influence their distribution in particular area of the littoral zone [36]. Another reason behind this could be the different capacity of the limpet species to tolerate harsh environmental conditions. C. karachiensis can tolerate high desiccation and fluctuating temperature or salinity [8] more than S. siphonaria. The results of the present study revealed that $S$. siphonaria was the most abundant species at S-4 microsampling site (Figure 2). This sampling site is characterized by numerous channels and crevices and the underlying rocky substratum is covered with moderate algal growth, thus possibly providing better habitat for the siphonarian species which exhibits limited desiccation tolerance [36]. It was reported that the tolerance to desiccation stress in limpets was generally related to zonation patterns $[4,9]$, and the high-shore species tend to have a great tolerance [25]. This trend was quite clear even in the sub-Antarctic regions where desiccation stress is presumably low [37]. In the present study it was revealed that the S-4 and S-2 were wetter than other microsampling sites due to the presence of numerous channels, crevices, and dense algal cover over the rocky substratum which possibly provide protection to the inhabitants against high temperature and desiccation between the tides $[3,4,36]$. Further, the S-3 microsampling site showed very low population abundance of both species. It may be possible that the uneven rocky substratum of this site makes it an unsuitable habitat for limpet population since the unevenness of the substratum encumbers their homing movements [20]. It was also observed that the microsampling sites S- 4 and S- 5 have more crevices and flat substratum, respectively, than that of the remaining sites providing more space to the limpets which inhabit these sites. Similar results were observed from the interspecific comparisons (Table 2) which revealed that the high-shore species were more tolerant than the low-shore species $[1,3,28,38]$.

\section{Conclusions}

It is evident from the present study that C. karachiensis preferred to inhabit the spray zone, while the upper littoral zone of the intertidal was the most preferable habitat for $S$. siphonaria. Results of the present study showed that bare rocky substratum with fewer pools and puddles and moderate to less algal growth provides ideal habitat for limpet Cellana karachiensis. Fewer sharp edges with more puddles and dense algal cover on intertidal surface are not suitable habitat for this species, while Siphonaria siphonaria preferred the place where running channels, crevices, and algal growth are more. It also prefers rocky habitat with moderate pools and puddles or mostly wetter portion of flat rocky substratum.

\section{Conflict of Interests}

The authors declare that there is no conflict of interests.

\section{Acknowledgments}

The authors are thankful to the UGC, Government of India, for support through its CAS Programme. One of the authors
(Paresh Poriya) is thankful to UGC, Government of India, for a Meritorious Research Fellowship. Various related Government Agencies and non-Government organizations are also acknowledged for extending their support and active help during the study.

\section{References}

[1] S. Misra and R. Kundu, "Seasonal variations in population dynamics of key intertidal molluscs at two contrasting locations," Aquatic Ecology, vol. 39, no. 3, pp. 315-324, 2005.

[2] G. M. Branch, "Interspecific competition experience by South African patella species," Journal of Animal Ecology, vol. 45, no. 2, pp. 507-529, 1976.

[3] A. Vaghela and R. Kundu, "Spatiotemporal variation of hermit crab (Crustaceae: Decapoda) inhabiting rocky shore along Saurashtra coast, western part of India," Indian Journal of GeoMarine Science, vol. 41, pp. 146-151, 2012.

[4] B. Gohil, P. Poriya, and R. Kundu, "Status of Intertidal macro faunal and floral diversity of Dwarka Sea Coast in prospects of some environmental factor," Bionano Frontier, vol. 4, no. 2, pp. 290-293, 2011.

[5] R. T. Sarvaiya, "Studies on mollusca of Saurashtra coasts-1," Fishery Technology, vol. 1, pp. 27-32, 1977.

[6] G. M. Branch, "The biology of limpet," Oceanography and Marine Biology Annual Review, vol. 19, pp. 235-380, 1981.

[7] S. Sukumaran and S. Krishnaswamy, "Reactions of Cellana radiata (Bom) (Gastropoda) to salinity changes," Proceedings of the Indian Academy of Sciences B, vol. 54, no. 3, pp. 122-129, 1962.

[8] M. B. Rao and P. N. Ganpati, "Resistance of limpet Cellana radiata (Born) to variations in temperature, salinity and desiccation," Proceedings of the Indian National Science Academy B, vol. 38, pp. 349-355, 1972.

[9] T. G. Wolcott, "Physiological ecology and intertidal zonation in limpets (Acmaea): a critical look at limiting factors," The Biological Bulletin, vol. 145, no. 2, pp. 389-422, 1973.

[10] A. J. Underwood, “The ecology of intertidal gastropods," Advances in Marine Biology, vol. 16, pp. 111-210, 1979.

[11] A. Cook, O. S. Bamford, J. D. B. Freeman, and D. J. Teideman, "A study of the homing habit of the limpet," Animal Behaviour, vol. 17, no. 2, pp. 330-339, 1969.

[12] J. H. Orton, "Observations on patella vulgata. Part III. Habitat and habits," Journal of the Marine Biological Association of the UK, vol. 16, no. 1, pp. 277-288, 1929.

[13] C. M. Eaton, "The activity and food of the file limpet Acmaea limatula," Veliger, vol. 11, supplement, pp. 5-12, 1968.

[14] R. Black, "Population regulation in the intertidal limpet Patelloida alticostata (Angas, 1865)," Oecologia, vol. 30, no. 1, pp. 922, 1977.

[15] S. B. Cook and C. B. Cook, "Directionality in the trail-following response of the pulmonate limpet Siphonaria alternata," Marine \& Freshwater Behaviour \& Physiology, vol. 3, no. 3, pp. 147-155, 1975.

[16] S. B. Cook and C. B. Cook, "Tidal amplitude and activity in the pulmonate limpets Siphonaria normalis (Gould) and $S$. alternata (Say)," Journal of Experimental Marine Biology and Ecology, vol. 35, no. 2, pp. 119-136, 1978.

[17] H. Suryannrayan and N. B. Nair, "Seasonal variations in biochemical constituents of Cellana radiata (Born)," Indian Journal of Marine Sciences, vol. 5, pp. 125-128, 1976. 
[18] P. C. Malli, M. N. Prasad, and A. P. Mansuri, "The response of the limpets Cellana radiata (Born) and Siphonaria siphonaria (Sowerby) of Saurashtra coast to desiccation and waters of different salinity," Journal of Animal Morphology \& Physiology, vol. 29, no. 1-2, pp. 71-77, 1982.

[19] M. N. Prasad and A. P. Mansuri, "Population density of the limpet, Cellana radiata (Born) in polluted waters at Porbandar, West coast of India," Indian Journal of Marine Sciences, vol. 11, pp. 180-181, 1982.

[20] B. Gohil and R. Kundu, "Ecological status of Cellana radiata at Dwarka coast, Gujarat, India," Research Journal of Recent Sciences, vol. 2, no. 5, pp. 1-5, 2013.

[21] J. Stimson, "Territorial behavior of the owl limpet, Lottia gigantean," Ecology, vol. 51, no. 1, pp. 113-118, 1970.

[22] D. T. Blackmore, "Studies of Patella vulgata L. II. Seasonal variation in biochemical composition," Journal of Experimental Marine Biology and Ecology, vol. 3, no. 3, pp. 231-245, 1969.

[23] G. J. Vermeij, "Morphological patterns in high-intertidal gastropods: adaptive strategies and their limitations," Marine Biology, vol. 20, no. 4, pp. 319-346, 1973.

[24] M. Balaparameswara Rao and P. N. Ganapati, "Ecological studies on a tropical limpet Cellana radiata," Marine Biology, vol. 9, no. 2, pp. 109-114, 1971.

[25] G. M. Branch, "Ecology of Patella species from the Cape peninsula, South Africa. IV. Desiccation," Marine Biology, vol. 32, no. 2, pp. 179-188, 1975.

[26] R. Misra, Ecology Work Book, Oxford \& IBH, Calcutta, India, 1968.

[27] R. R. Sokal and F. J. Rohlf, Introduction to Biostatistics, Dover Publications, 1987.

[28] A. Vaghela, P. Bhadja, J. Ramoliya, N. Patel, and R. Kundu, "Seasonal variations in the water quality, diversity and population ecology of intertidal macrofauna at an industrially influenced coast," Water Science and Technology, vol. 61, no. 6, pp. 1505$1514,2010$.

[29] B. Vakani, Studies on the structure of a rocky and muddy intertidal assemblage [M. Phil. Thesis], Saurashtra University, Rajkot, India, 2013.

[30] J. P. Sutherland, "Dynamics of high and low populations of the limpet, Acmaea scabra (Gould)," Ecological Monographs, vol. 40, no. 2, pp. 169-188, 1970.

[31] R. G. Creese, "An analysis of distribution and abundance of populations of the high-shore limpet, Notoacmea petterdi (tenison-woods)," Oecologia, vol. 45, no. 2, pp. 252-260, 1980.

[32] M. N. Prasad, P. C. Malli, and A. P. Mansuri, The Color Banding Pattern and Frequencies in a Tropical Limpet Cellana radiata (Born) on the Veraval Coast of Western India, The Marine Biological Association of India, 1984.

[33] G. M. Branch, "The ecology of Patella Linnaeus from the Cape Peninsula, South Africa. I. Zonation, movements and feeding," Zoologica Africana, vol. 6, no. 1, pp. 1-38, 1971.

[34] E. A. Kay and W. Magruder, The Biology of Opihi, Department of Planning and Development, Honolulu, Hawaii, USA, 1977.

[35] S. B. Cook, "The role of the home scar in pulmonate limpets," Bulletin American Malacological Union, vol. 1976, pp. 34-37, 1976.

[36] R. G. Creese and A. J. Underwood, "Analysis of inter- and intraspecific competition amongst intertidal limpets with different methods of feeding," Oecologia, vol. 53, no. 3, pp. 337-346, 1982.
[37] R. D. Simpson, "Physical and biotic factors limiting the distribution and abundance of littoral molluscs on Macquarje Island (sub-Antarctic)," Journal of Experimental Marine Biology and Ecology, vol. 21, no. 1, pp. 11-49, 1976.

[38] P. S. Davies, "Physiological ecology of Patella. III. Desiccation effects," Journal of the Marine Biological Association of the UK, vol. 49, no. 2, pp. 291-304, 1969. 

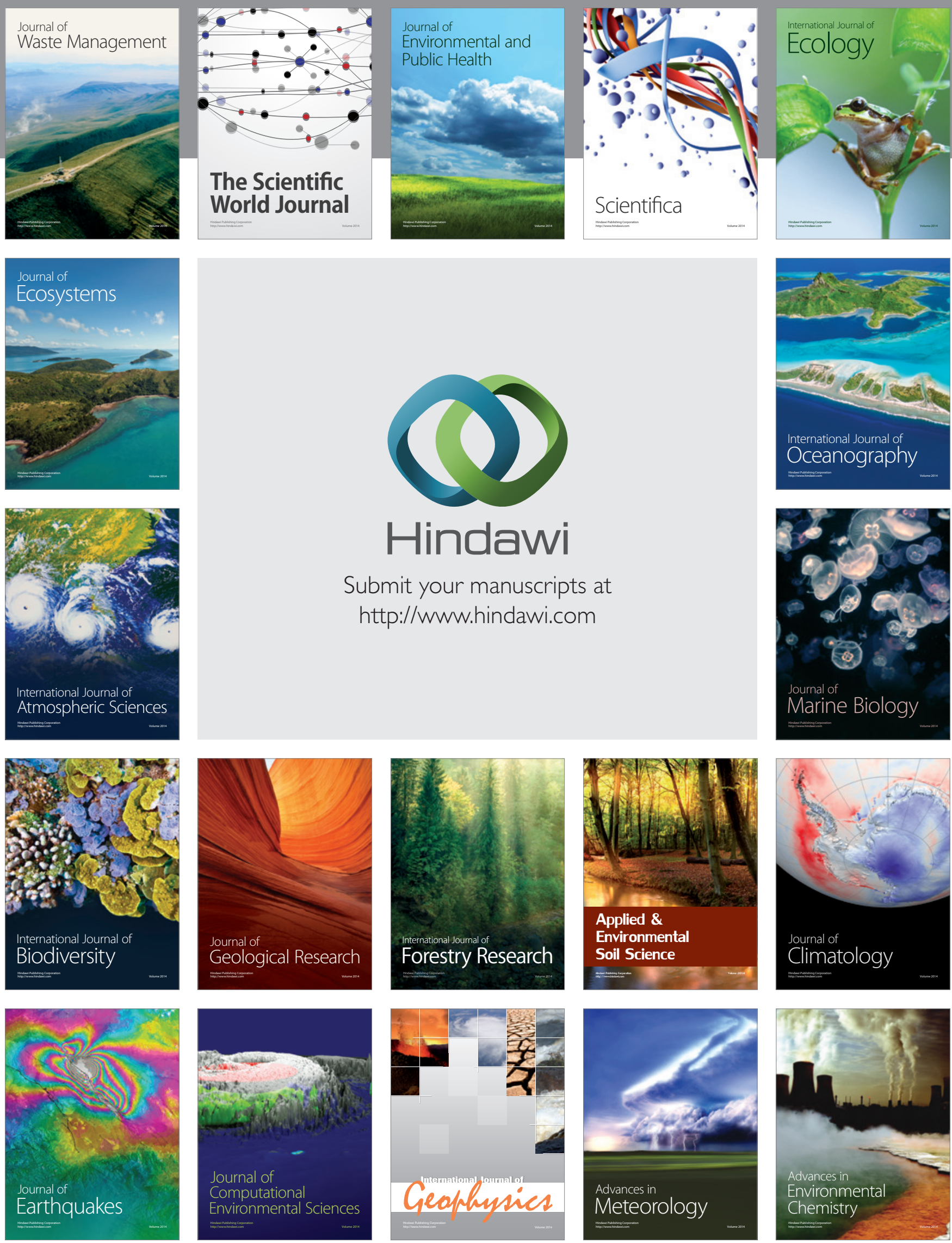